\title{
Honduras: elecciones y democracia
}

Juan Arancibia Córdova

$\mathrm{L}$

a inestabilidad politica ha sido una constante dolorosa en el devenir histórico del país, lo que ha impedido que los hondureñosforjemosuna verdadera conciencia de nacionalidad, $y$ el desenvolvimiento de instituciones libres en el marco del derecho.

Un análisis de esa situación traumática nos demuestra que desde 1821 hasta la fecha, pasando por la etapa en que nos erigimos en estado independiente, han habido 385 acciones armadas, de carácter interno, con derramamientos de sangre, entre revueltas, montoneras y golpes de Estado. Enese mismo periodosehan producido 126 cambios de gobiernos, entre transiciones ordenadas $y$ alteraciones irregulares, y han regido 16 constitucio- nes, incluyendolastresfederales y la que este año aprobarán los constituyentes. ${ }^{1}$

\section{EL CARÁCTER DE LA DEMOCRACIA \\ HONDUREÑA}

En las páginas que siguen haré un análisis somero del proceso electoral hondureño y las perspectivas del nuevo gobierno y del país; para ello arrancaré de algunas afirmaciones generales que serán brevemente argumentadas.

\footnotetext{
' Discurso de toma de posesión de Roberto Suazo Córdova, La Tribuna, 30 de enero de 1989 , pp. 30-31.
} 


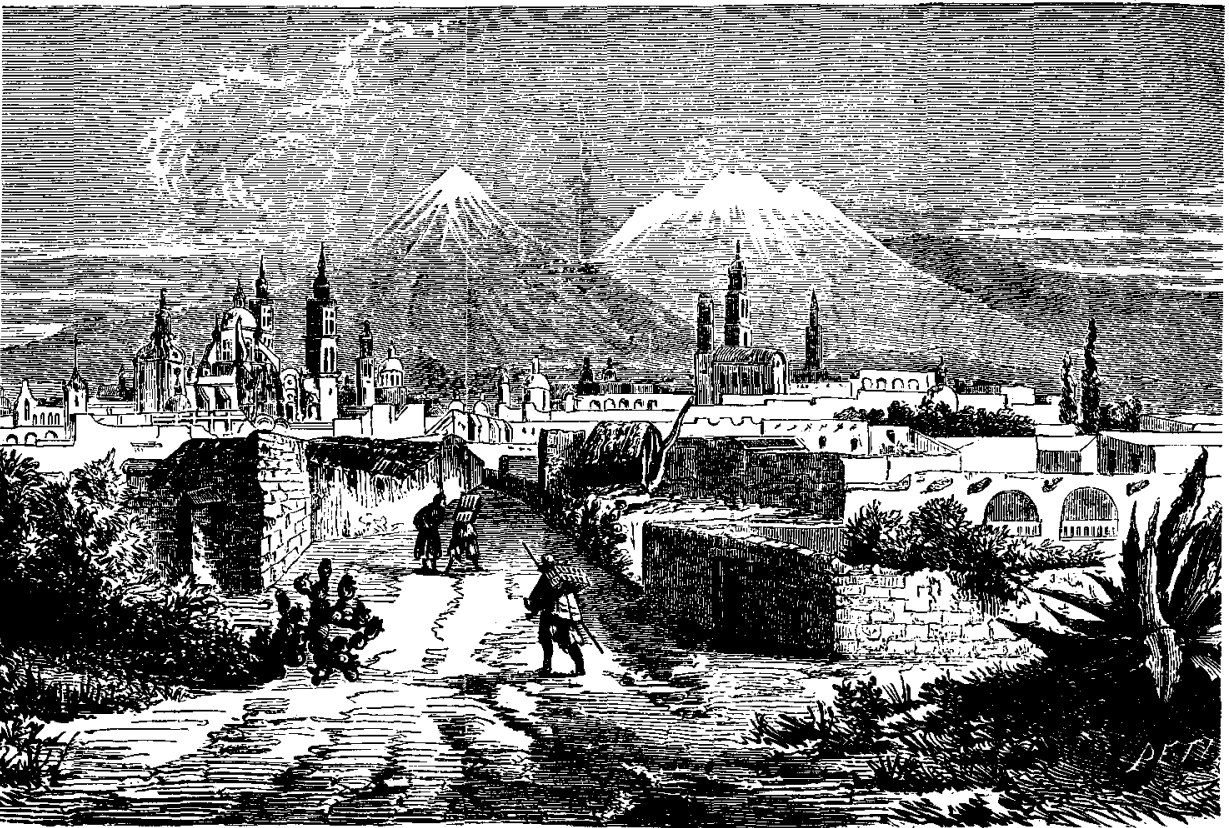

La cita con que hemos iniciado este trabajo nos ahorra la argumentación relativa a la inestabilidad política, un total de 126 gobiemos para 160 años nos habla de que cada uno de ellos duró como promedio menos de un año y medio y quince constituciones para ese mismo periodo representan menos de once años de vigencia para cada una. EI problema es que con tantos golpes de Estado y cambios de gobierno, en la práctica las constituciones no han regido o lo han hecho parcialmente.

¿Cómo se explica este proceso constante de dominación sin hegemonía?

Las causas son varias, aunque hay una central que tiene que ver con el carácter colonial y dependiente (de enclave) del desarrollo histórico hondureño.

a) Honduras arriba a su independencia como un ente histórico poco articulado, un territorio poco poblado, con escasas actividades económicas de significación, clases sociales escasas y localmente desarrolladas y poca o nula comunicación y relación entre sus diversas regiones. En el momento en que es necesario fundar, construir lo nacional y su Estado, no hay un grupo social, local o nacional que tenga la potencia económica y política para hacerlo. El resultado es el localismo, el regionalismo, el caudillismo y la inestabilidad.

b) El capitalismo adviene a Honduras por la vía del capital extranjero y el enclave. El desarrollo interno, más la ayuda de Guatemala y El Salvador, hacen posible la revolución liberal en Honduras. Esta revolución genera condiciones institucionales, legales y aun infraestructurales (como caminos) para el desarrollo capitalista, pero no encuentra al sector social, a la clase capaz de generar ese desarrollo y éste no ocurrirá hasta la 
penetración, en los últimos años del siglo pasado y los primeros del actual, del capital norteamericano en la explotación bananera. El capital extranjero creará y se expandirá luego a otros servicios, a la banca, a la industria liviana y al comercio.

c) El capital extranjero creará un enclave económico, que controlará los núcleos dinámicos de la economía, el grueso de las exportaciones, la industria manufacturera etc. Ese enclave dejará prácticamente intactas las relaciones de producción en el resto de la economía y del país (se ubica en la zona norte) y no generará cadenas productivas que lo engarcen con los productores locales.

d) El enclave generará capitalismo en su espacio y bloqueará su desarrollo en el resto. Pero no sólo es el bloqueo de las relaciones salariales y mercantiles, sino también de las clases que portan estas relaciones y las reproducen.

La clase dominante quedará marginada de las actividades dinámicas y no sufrirá un proceso de transformación y desarollo de tipo capitalista permaneciendo, hasta muy entrado este siglo, en una condición no capitalista.

Bloqueada en su desarrollo, la clase dominante puede dominar pero no puede construir consensos, hegemonía, estabilidady democracia; tampocolasclases subalternas pueden luchar eficazmente por ello, se encuentran igualmente bloquedas y subdesarrolladas.

e) Marginada de las actividades económicas dinámicas, la clase dominante enfrenta al Estado como a un botín a repartir y por el cual luchar. El Estado es un objetivo en sí, en el aprovechamiento de los escasos ingresos con que cuenta.

$f$ En síntesis, lo colonial y lo dependiente no permiten la construcción de lo nacional y "jibarizan" el desarrollo de lo estatal.
Al no desarrollarse el mercado interno, las relaciones salariales y mercantiles que lo sustentan, y particularmente las clases sociales que lo concretan y lo reproducen, la democracia y la hegemonía que la acompañan no pueden ocurrir. Son frustradas aspiraciones, sueños volátiles, que se esfuman en el cuartelazo de la madrugada, en la montonera caudillista o en el fraude electoral.

El doctor Roberto Suazo Córdova sería el tercer presidente elegido más o menos democráticamente en lo que iba del siglo y el segundo que terminaría normalmente su mandato.

¿Cuál es el origen de la democracia electoral hondureña reciente?

a) La dictadura del general Tiburcio Carias Andino (1933-49) puso fin a las guerras civiles entre las clases dominantes. No obstante lo anterior, no se consiguió acabar con los golpes de Estado y el fraude electoral. Cuando se produjo el triunfo sandinista en Nicaragua en 1979 , el país vivía bajo una dictadura militar.

En 1980 los hondureños concurrieron masivamente a las urnas para elegir una Asamblea Nacional Constituyente que puso fin formal al gobierno militar; esa misma asamblea eligió al general Policarpo Paz García como presidente provisional, con lo cual mantuvo a los militares en el gobierno hasta enero de 1982.

En noviembre de 1981, de 1985 y de 1989 , los hondureños han elegido presidentes de la república, con una participación de electores ejemplar por su número, ya que en todas ellas ha votado más de $80 \%$ de los inscritos.

b) Los militares debieron entregar el gobierno acosados por diversosfactores.

De una parte, la presión de los grupos económicos y políticos tradicionales del país que estaban cansados de no gobernar directamente y sin que hubiera (según ellos) reales razones para no hacerlo. 
De otra, las presiones del pueblo agobiado por la corrupción, el mal gobierno y sus problemas vitales no solucionados.

Y finalmente, las presiones norteamericanas (de la administración Carter) para una democratización del área, considerada elemento esencial para contener la ola revolucionaria, de la cual la revolución sandinista era la avanzada.

Sumadas distintas determinantes internas y externas, se consiguió realizar en 1980 elecciones relativamente limpias y que sus resultados fueran respetados.

Sin la lucha revolucionaria en la regiôn y sin la presión norteamericana, probablemente la democracia hondureña no existiría, seria más frágil o ya hubiese sido rota.

El ejército hondureño de los tiempos modernos fue creado por los norteamericanos en 1954 , aunque ya habían iniciado sus esfuerzos a comienzó de los años cuarenta, con diversos intentos de profesionalizarlo progresivamente. En mayo de 1954 se firmó el Tratado. Bilateral de Ayuda Militar y se creó el $1^{\text {ex }}$ batallón de infantería. Después de 1954 el ejército intervendrá institucionalmente en la vida política del país.

En ese contexto el ejército da su primer golpe de Estado en 1956 y entrega el gobiemo en 1957. En 1963 da un nuevo golpe de Estado, entrega el gobierno en 1971, en 1972 retoma el control del gobierno para entregarlo en 1982, pero en el interin se dan golpes de Estado en 1975 y en 1978.

Los militares no llegaron al gobierno por capricho, lo hicieron para llenar un vacío de poder real, para resolver en una u otra dirección la ausencia de hegemonía en el interior de la clase dominante, cuestión que se ha traducido en la ausencia de estabilidad política y democracia.
Es por ese vacío de poder que los militares tienen una cuota esencial de éste en el país y a veces lo ejercen desde el propio gobierno. Es por ello también que aun cuando los militares entregan el gobierno a los civiles no les entregan el poder, ya que éste se construye y existe, pero no se puede traspasar por un mero acto formal.

Estan clara esta situación, que cuando se presentan conflictos constitucionales - cuando una huelga importante no puede ser resuelta, se acude a los militares para que arbitren y decidan.

Pero no sólo lo anterior, ya que la Constitución consagra de diversas maneras esa situación, por ejemplo, al dejar al presidente como comandante supremo, pero al jefe de las fuerzas armadas como jefe real, al establecer un Consejo Nacional de Seguridad con seis militares y cuatro civiles, al dar completa autonomía y secreto al presupuesto del aparato militar, al dar completa autonomía en nombramientos, ascensos y retiros de los oficiales, etcétera.

Durante varios momentos y en muchas circunstancias, los militares han conducido la política exterior del país en la década de los ochenta; decidieron realmente todo lo relacionado con las conexiones militares con Estados Unidos y con la contra y también con Nicaragua y El Salvador. Tomaron decisiones sobre huelgas, reformas constitucionales y aun salieron armados a la calle para fijar el precio del dólar en el mercado paralelo.

Pero los militares no son los únicos que compiten con la débil sociedad civil hondureña, también Estados Unidos detenta una cuota creciente del poder económico y político. Su origen es el enclave económico. Su desarrollo y consolidación en la coyuntura actual está dada por el enclave militar y la moderna dependencia incluida la deuda externa, 


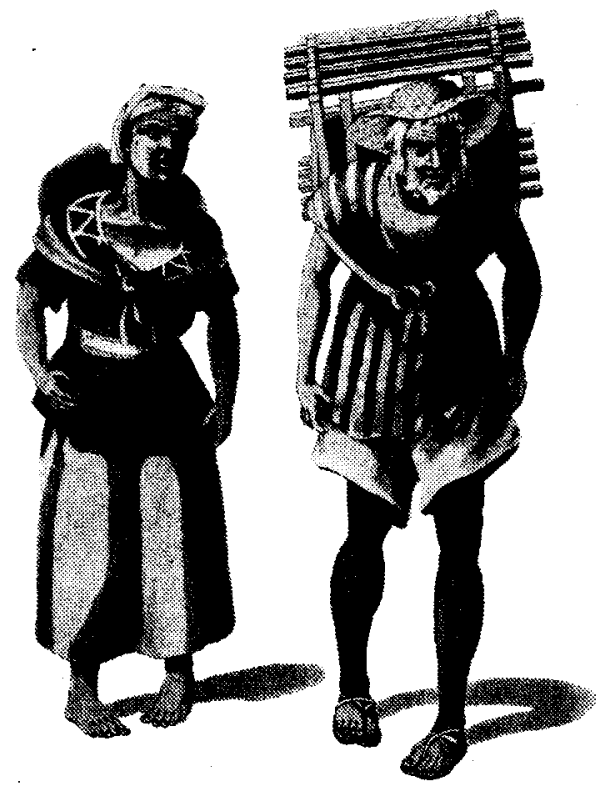

1

y el desarrollo en los ochenta de un ejército y una economía subsidiadas por Estados Unidos.

La fortaleza del poder de Estados Unidos en Honduras es un hecholargamente documentado y analizado a nivel internacional y no nos ocuparemos más de ello en este trabajo.

En Honduras, los partidos llamados tradicionales, el Liberal y el Nacional, dominan la escena política del país en el siglo actual.

Juntos suponen, $95 \%$ de los votos legalmente emitidos en la década de los ochenta. El 5\% restante se divide entre el Partido de Innovación Nacional y Unidad Social Demócrata (PINU-SD) y la Democracia Cristiana.

EI Partido Liberal ganó las elecciones de 1980,1981 y 1985 y el Partido Nacional acaba de ganarlas de noviembre de 1989.

¿Cómo explicar que partidos conservadores ganen las elecciones, que los partidos de centro no logren crecer y que no haya una izquierda electoral?
Estosí requiereuna explicación ya que Honduras es uno de los tres países más pobres de América Latina, con 50\% de analfabetismo; con casi $30 \%$ de desempleados, con casi $50 \%$ de subempleados, con casi $70 \%$ de la población en la pobreza, y otros índices sociales y económicos igualmente pavorosos.

La explicación se encuentra en múltiples factores, desde la histórica división entre colorados y azules o liberales y nacionales válida en la política y en la guerra, pasando por el control caudillista en los campos y poblados menores y por el clientelismo urbano. La prédica constante de carácter anticomunista. El asedio permanente a las organizaciones de masas, el asesinato de sus dirigentes y la destrucción de las organizaciones. El trabajo permanente y ya histórico del llamado sindicalismo libre y del socialcristianismo en los sindicatos urbanos y rurales. El reformismo desarrollado por los liberales entre 1957 y por los militares entre 1972 y 1975 (particularmente la 
reforma agraria). La exclusión forzada, legal o real, de la izquierda del espacio político legal y electoral, además de la incapacidad de las fuerzas de centro y de izquierda para proponer y desarrollarun trabajo adecuado. No podrían descartarse como factores explicativos el analfabetismo, el carácter rural de la mayoría de la población, el poco y lento desarrollo de las relaciones salariales y la propia ausencia de la democracia; cuestión a la cual ya intentamos darle explicación y que, además, el poder militar ha contribuido a fomentar con sus casi 20 años de gobierno reciente.

\section{LAS ELECCIONES RECIENTES Y LAS PERSPECTIVAS}

Las últimas elecciones de noviembre de 1989 fueron ganadas por Rafael Leonardo Callejas y su Partido Nacional.

Callejas obtuvo alrededor de $52 \%$ de los votos, los liberales $43 \%$ y el resto se reparte entre el PINU-SD con $1.8 \%$ y la Democracia Cristiana con 1.4 por ciento.

Los nacionales no habían podido ganar desde que se retornó a los procesos electorales en 1980. En 1985 Callejas había sido el candidato individualmente más votado, pero la suma de los votos de los varios candidatos liberales le dio el triunfo a José Azcona Hoyo (hubo simultáneamente elecciones primarias y nacionales).

El triunfo de Callejas se explica por el fracaso de los dos gobiernos liberales para manejar la crisis económica del país y atenuar las condiciones de desempleo y pobreza de la mayoría de la población.

La población está buscando en Callejas una alternativa. Esta alternativa es la persona, ya que no hay programa de gobierno, sino declaraciones generales $\mathrm{y}$ vagas.
Esto no es extraño ya que la política del país es caudillista, clientelista y carente de contenido programático. Las campañas políticas se centran en las personas y no en los programas, éstos son reemplazados por canciones y diversos tipos de mensajes publicitarios con técnicas de marketing, incluso en esta campaña se incluyó el elemento sexual, ya que mujeres ligeras de ropa anunciaban a los candidatos.

El Partido Nacional no sólo controla el ejecutivo, sino la Cámara de Diputados (parlamento unicameral) y la Corte Suprema de Justicia y también el Tribunal Electoral.

Callejas ha designado un gabinete tecnocrático-empresarial, algunos decuyos miembros clave, al igual que el propio Callejas, han estado ligados al proyecto de APROH (Asociación para el Progreso de Honduras) ${ }^{2}$ o a la AID.

Ambas ligazones sitúan al nuevo gobierno en una línea de derecha neoliberal (con todas las particularidades que esto pueda tener en el país) y en una perspectiva estatal de seguridad nacional.

APROH fue un organismo creado y lidereado por el general Álvarez Martínez y Callejas fue secretario de asuntos laborales y campesinos del mismo. APROH pretendió vincular más estrechamenteal país con Estados Unidos, incluso solicitó fuese convertido en Protectorado (lo que de hecho ha ocurrido); quería liberalizar y privatizar, al tiempo que reprimir y controlar a la población. Por ejemplo, propuso transformar a 170000 campesinos sin tierra en cooperativistas forestales encargados de la seguridad de sus

${ }^{2}$ La APROH reunía a empresarios, políticos, intelectuales y dirigentes populares y era un organismo suprapartidario con un proyecto de desarrollo conservador, modernizante y de seguridad nacional. 
áreas (algo como patrullas de autodefensa).

A inicios del año 1989 se conoció en el país un documento llamado "Mejorando el clima para la inversión en Honduras". El Consejo Hondureño de la Empresa Privada presentó ese documento al "diálogo nacional". Radio América informó que el documento fue elaborado por la firma Robert Nathan Association en colaboración de Benjamín Villanueva asesor de la AID y del COHEP, designado ministro de Hacienda y Crédito Público por Callejas en enero de 1990.

El documento sugería la devaluación del lempira y dar máxima prioridad a las exportaciones.

Proponía realizar en 1989 una política de transición por el año electoral, dicha política contendría las siguientes medidas:

-Reducir el déficit fiscal, no creando empleos e incrementando las recaudaciones aduaneras.

- Controlar los préstamos y elevar las tasas de interés.

-Incrementar el monto de los CETRAS (certificados equivalente a dólares transados en el mercado libre).

- Crear una tasa de cambio turística.

- Promover leyes favorables a la comunidad empresarial.

-Aprobar leyes para facilitar la inversión, especialmente la extranjera.

-Disminuir e impedir la participación del sector público como empresario.

- Mejorar el manejo del sector público.

Este documento es importante porque fue asumido por el empresariado a través del COHEP, y porque se acaba de anunciar un plan de choque que incluye:

- La devaluación del lempira de su paridad de dos lempiras $=1$ dólar que duró más de medio siglo. Se mantiene la anterior paridad para el pago de la deuda externa (casi toda pública).

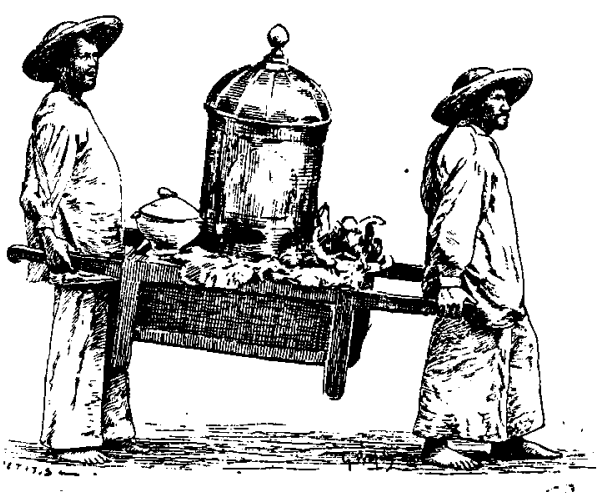

-Incremento de 50\% del impuesto sobre ventas.

-Alza de 35\% de impuesto sobre la renta.

$-20 \%$ de impuesto a los combustibles.

-Incremento de $33 \%$ del impuesto a las exportaciones.

-Incremento de $100 \%$ a los impuestos de matrícula a los vehículos y al peaje de carreteras.

-Eliminación de exoneraciones fiscales.

El plan apunta en lo inmediato a reducir el déficit fiscal de 500 millones de dólares e igual a un tercio del presupuesto. Bajar la inflación (de 11\% en 1989, pero en alza). Estimular a los exportadores. El plan golpea duramente a la industria y a los sectores populares. A la primera por los incrementos de costos y la pérdida de franquicias fiscales, a los segundos por la inflación y pérdida de empleos que ocurrirán.

El plan contempla algunos millones de dólares para subsidiar el precio del transporte urbano de pasajeros; a las familias con niños en edad escolar; a los precios de productos básicos para familias pobres, y al apoyo al banco de vi- 
vienda y a un programa de generación de empleos.

Este plan económico que se inicia y del cual el paquete arriba comentado es una parte, cuenta con el apoyo del empresariado local y transnacional y con el apoyo evidente de organismos como el FMI, el BM y la AID; es más, en ellos se ha originado. Estos apoyos y acuerdos no lo exentan de contradicciones pero a pesar de ellas será aplicado.

\section{A MODO DE CONCLUSION}

Se ha planteado que Rafael Leonardo Callejas representa a una nueva derecha en Honduras, probablemente esto es cierto, pero falta definir cuál es lo nuevo.

Se trata de una derecha más tecnocrática, menos oligárquica en el sentido tradicional, es decir, menos apegada a los sectores económicos tradicionales.

Es nueva en su intento por liberalizar la economía, liquidando el proteccionismo, el papel del Estado empresario. Se trata de una modernización con marcadas tendencias neoliberales, que abandona el mercado interno y en cierta forma al mercado común centroamericano.

Es nueva en sus técnicas de marketing, en su discurso de tonalidades populistas, en una cierta ruptura con los políticos tradicionales.

Pero aún en el marco de su discurso de tono populista y concertador es una derecha,'más radical, más partidaria de una mayor dependencia, de una mayor integración al mercado mundial.

Las perspectivas económicas del país no son buenas. Antes de las elecciones en Nicaragua ya se había recortado la ayuda militar y económica; después de la derrota electoral sandinista las perspectivas de apoyo norteamericano han empeorado. Tan escasa era la disposi- ción estadunidense que Callejas amenazó con convertir la base militar de Palmerola $^{3}$ y su aeropuerto en el nuevo aeropuerto civil de la capital del país, si la ayuda norteamericana no crecía y se flexibilizaba.

La aplicación de las nuevas medidas económicas generará más desempleo, más inflación y recesión económica en algunos rubros de la economía, aunque es posible que incrementen las exportaciones.

Las perspectivas políticas no son tampoco alentadoras. El nuevo gobierno operará en un contexto regional de derechización y en un marco de mayor agresividad imperialista.

Los antecedentes políticos de Callejas y sus principales colaboradores, los hacen responsables de la política de represión y desa pariciones del periodo 198284. Aparecen como partidarios de un estado de seguridad nacional y como estrechos aliados de Estados Unidos.

Es viable esperar una majyor represión económica, política y física a las mayorías populares.

También debe acentuarse el intento por introducir más aceleradamente el solidarismo como reemplazo y destrucción del sindicalismo.

Las medidas asistencialistas del plan económico no lograrán paliar sus efectos regresivos sobre los niveles de vida. Debemos esperar una intensificación de las contradicciones sociales; una agudización de la lucha política y un incremento de la represión estatal.

El poder político seguirá en manos de los militares y en la embajada norteamericana, de manera sustancial, pero ahora con un mayor acuerdo con el gobierno civil que en la etapa anterior.

${ }^{3}$ Sede de la Fuerza de Tarea Bravo, responsable de las maniobras conjuntas. 